\title{
LA DIMENSIÓN CONSTITUCIONAL DEL PRINCIPIO DE TRANSPARENCIA $Y$ EL DERECHO DE INFORMACIÓN ACTIVA
}

GERARDO RUIZ-RICO RUIZ 
SUMARIO:

1.- INTRODUCCIÓN: LA CONEXIDAD CONSTITUCIONAL DEL PRINCIPIO DE TRANSPARENCIA INFORMATIVA. 2.- FORMULACIONES DE LA «INFORMACIÓN ACTIVA» DERIVADAS DE LA CONSTITUCIÓN. 3.- LA LEY 19/2013, DE 9 DE DICIEMBRE, DE TRANSPARENCIA, ACCESO A LA INFORMACIÓN PÚBLICA Y BUEN GOBIERNO. UNA REFORMA PARCIALMENTE INNOVADORA. 3.1.- Sobre la configuración legislativa del principio de transparencia. 3.2.- La Publicidad «activa» como dimensión instrumental del principio legal de Transparencia. 3.3.- La garantía de las obligaciones de información activa: el Consejo de Transparencia y Buen Gobierno. 3.4.- Los Ombudsmen y el control de la transparencia. 4.- EL DEBER DE TRANSPARENCIA INFORMATIVA EN LA ESFERA DEL PODER JUDICIAL. 5.- EN TORNO AL DEBATE SOBRE SI LA TRANSPARENCIA ES UN DERECHO FUNDAMENTAL, DERIVADO DIRECTAMENTE DE LA CONSTITUCIÓN. 6.- BALANCE, DUDAS Y ALGUNAS CRÍTICAS SOBRE EL DERECHO DE INFORMACIÓN ACTIVA EN LA LEY $19 / 2013$. 


\title{
LA DIMENSIÓN CONSTITUCIONAL DEL PRINCIPIO DE TRANSPARENCIA Y EL DERECHO DE INFORMACIÓN ACTIVA
}

\author{
GERARDO RUIZ-RICO RUIZ1 \\ Catedrático de Derecho Constitucional \\ Universidad de Jaén
}

\section{INTRODUCCIÓN: LA CONEXIDAD CONSTITUCIONAL DEL PRINCIPIO DE TRANSPARENCIA INFORMATIVA}

La transparencia se ha convertido en un ideal imprescindible y de carácter global en la configuración contemporánea del Estado de Derecho ${ }^{2}$. Sin embargo, esta importancia no se ha visto contrastada por la existencia de un marco definido en la esfera normativa constitucional. La ausencia de referencias sobre el principio de transparencia identifica a la mayor parte de los textos constitucionales. Pero este dato no impide en todo caso defender su asociación, indefectiblemente, con otros principios y valores característicos de un Estado democrático (participación, pluralismo, control, rendi-

1 Catedrático de Derecho Constitucional. Departamento de Derecho Público. Facultad de Ciencias Sociales y Jurídicas. Universidad de Jaén. Campus Las Lagunillas s/n. 23071 - Jaén. Email: gruiz@ujaen. es. Código Orcid:0000-0002-5505-2591

2 La exigencia de transparencia representa además una de las reglas y principios prioritarios de lo que se conoce como Buen Gobierno. En este sentido, el Libro Blanco sobre la Gobernanza de la Unión Europea (2001) nos permite comprobar cómo existe un espacio compartido entre aquélla y la Buena Administración, en la medida en que ambas nociones plantean la necesidad de modificar los patrones de conducta de los poderes públicos en sus relaciones con la ciudadanía. La metodología se plasma en los vehículos y canales de comunicación, participación e información que se puedan implantar en los procesos de toma de decisiones de las instituciones políticas y administrativas. El objetivo final —en el que coinciden asimismo los dos principios - se centra en mejorar los estándares de eficiencia y eficacia en la consecución del interés general y el bienestar de la sociedad. Vid. el estudio preliminar que se contiene en la obra colectiva. La Ley de Transparencia, Acceso a la Información, Publica y Buen Gobierno, (I. Wences, M. Kölling, S. Ragone (coords.), Centro de Estudios Políticos y Constitucionales, EPC, Madrid, 2014. 
ción cuentas) ${ }^{3}$. Más aún, se podría afirmar que la transparencia no sería sino una consecuencia de la propia democracia, entendida como procedimiento en la toma de decisiones y como método que permite la rendición de cuentas y la evaluación social sobre el impacto que aquéllas producen sobre el interés público ${ }^{4}$.

Convendría hacer alguna precisión metodológica de partida, a propósito de la fuerte dosis de ambigüedad e indeterminación sustantiva sobre la eficacia y alcance que comporta a priori el principio de transparencia. De ahí que sea necesario delimitar las dos dimensiones esenciales —y complementarias — sobre los que se proyecta. De un lado, la llamada «publicidad activa», que pivota sobre una obligación de los poderes públicos a suministrar una información que podríamos adjetivar como institucional. En segundo lugar, una vertiente «subjetiva» de la publicidad, que se plasma en forma de acceso a una información, en potencia y cualitativamente de mayor amplitud, que los ciudadanos tienen derecho a reclamar a esos mismos órganos que componen el conjunto de Administraciones Públicas. A veces la frontera entre una y otra vertiente de la transparencia no está trazada de una manera muy nítida. La línea divisoria parece venir marcada por el sujeto destinatario del mandato de transparencia; mientras en la publicidad activa es la información que se genera y publicita por la propia Administración, en el derecho de acceso la iniciativa corre a cuenta del particular.

La conexidad del principio de transparencia con algunos de los elementos identitarios de la norma constitucional empieza a cobrar forma en la relación que tiene con los presupuestos programáticos que la inspiran. La base constitucional de la transparencia, entendida como condición y consecuencia de un modelo democrático de organización política, comienza a vislumbrarse en el Preámbulo de la Constitución, donde se propone como compromiso fundacional del Estado el establecimiento de

3 Además de esta recepción indirecta en el nivel superior del ordenamiento, la transparencia informativa encuentra expresividad y fundamento en la esfera convencional, de la que toman nota los legisladores nacionales. Como destacables en el ámbito regional europeo se podrían citar, entre otros, la Recomendación del Consejo de Europa de 1981 sobre el Acceso a la Información en manos de las Autoridades Públicas; y principalmente el Convenio del Consejo de Europa sobre Acceso a los Documentos Públicos (2009), todavía sin firmar ni ratificar por España. En el ordenamiento de la Unión Europea, el Reglamento 1049/2001, del Parlamento europeo y del Consejo de 30 de mayo de 2001, relativo al acceso del público a los documentos, es la norma principal de referencia en materia de transparencia; de interés igualmente la Recomendación (Rec. 2002,2) del Comité de Ministros a los Estados miembros sobre el acceso a los documentos oficiales, de 21 de febrero de 2002. En sede de tratados «fundacionales», y a partir del Tratado de Lisboa (2007), el artículo 15.3 del TFUE va a reconocer el derecho a la información, ante las instituciones de la Unión, en «cualquiera que sea su soporte», además de imponer la publicidad de las sesiones de Parlamento Europeo $y$ del Consejo.

4 En esta misma línea apunta la afirmación de Marc Carrillo: «la transparencia en la gestión de los asuntos públicos es una consecuencia de la democracia como procedimiento»; un procedimiento en definitiva que será configurado legalmente y desde el cual se marcan las reglas — vinculantes- del funcionamiento y la actividad de los poderes públicos. Vid. Vid. M. Carrillo, «Transparencia y derechos de acceso a la información en las administraciones públicas», en Parlamento y Constitución. Anuario, núm. 17, 2015, p. 273. 
una «sociedad democrática avanzada»; también con el principio/mandato constitucional sobre la promoción de la participación en «la vida política, económica, cultural y social» (art. 9.2 CE). En todo caso, se hace patente más claramente en la conexión con los principios basilares que orientan el funcionamiento de la Administraciones Públicas, como la seguridad jurídica o la eficacia y eficiencia de los servicios públicos. Pero con seguridad resulta más intensa en cuanto presupuesto de la noción genérica de control, y más en específicamente de la capacidad de fiscalización que los ciudadanos aspiran a ejercer sobre las instituciones que los representan. La información parece, en esa segunda dimensión constitucional, un instrumento necesario para garantizar las posibilidades de una adecuada evaluación social de los actores institucionales y las políticas públicas que desde ellas se ponen en práctica; en definitiva, como condición sine qua non de la posterior rendición de cuentas, que es la expresión a fin de cuentas de una modalidad de participación que llega a afectar en potencia a la toma de decisiones públicas.

Pero la transparencia tiene un valor destacable sin duda como objetivo que indirectamente favorece la igualdad de las posiciones jurídicas de la ciudadanía ante los poderes públicos; sería el vehículo idóneo que permite neutralizar, mediante su visualización, aquellas prácticas clientelares que representan la antítesis de lo que debe ser un Estado de derecho. De este modo, la transparencia informativa se alinea con los dispositivos que este último proporciona en la lucha contra la corrupción, entendida como un fenómeno poliédrico y transversal que afecta de manera global a las entidades que operan desde y con la esfera de lo público.

La transparencia tiene finalmente una vinculación especial — casi simbióticacon el principio de la «Buena Administración»" ; en cierto modo incluso se podría afirmar que son dos principios que se superponen en cuanto a objetivos y finalidades intrínsecas. Algo similar sucede con el principio del «Buen Gobierno», donde la transparencia viene a actuar como instrumento que sirve para promocionar la participación y, como consecuencia también, para fortalecer la democracia; al reducir la

La bibliografía sobre la «Buena Administración» es abundante en la doctrina del Derecho Administrativo; menos en la de Derecho Constitucional. Una de las primeras aportaciones que conviene destacar sería la de J. Ponce-Solé, El principio de buena administración: discrecionalidad y procedimiento administrativo, Barcelona, Universitat de Barcelona, 1998. Entre los autores que han trabajado igualmente en este tema, podríamos mencionar a J. Rodríguez-Arana, «El derecho fundamental al buen gobierno y a la buena administración de instituciones públicas», en Revista de Estudios Locales, Madrid, núm. 100 (abr. 2007), p. 39-47, así como «la buena administración como principio y como derecho fundamental en europa misión jurídica», en Revista de Derecho y Ciencias Sociales, Bogotá, D.C. (Colombia) Colaboradores Externos Internacionales Núm. 6, Año 2013 enero-diciembre, pp. 23-56. Más recientemente, Javier Barnes, «Buena administración, principio democrático y procedimiento administrativo", en Revista Digital de Derecho Administrativo, n. ${ }^{\circ} 21$, primer semestre de 2019, pp. 77 a 123. Por nuestra parte, nos hemos ocupado del tema en G. Ruiz-Rico Ruiz, «El derecho a una buena administración. dimensiones constitucional y estatutaria». En El derecho a una buena administración y la ética pública. C. Ávila Rodríguez y F. Gutiérrez Rodríguez, Tirant lo Blanch, Valencia, 2011, pp. 55-76. 
desafección social que afecta a sus instituciones en tiempos de crisis de legitimación ${ }^{6}$.

Sin embargo, la «Buena Administración», como idea dotada de una autonomía conceptual, no ha sido general ni explícitamente formulada en los textos constitucionales; aunque la finalidad esencial a la que se orienta formarían parte del contenido y significado implícitos en otra serie de principios fundamentales de las Administraciones Públicas que sí han obtenido allí una formulación explícita: respeto por los intereses generales, principios de eficacia, jerarquía, descentralización, desconcentración, coordinación, y legalidad administrativa. La conexión directa de aquélla con el principio de transparencia se observa sin embargo en la esfera estatutaria, categoría normativa perteneciente al bloque de constitucionalidad. En algunos Estatutos de nueva generación (Cataluña, Andalucía) se puede reconocer la relevancia que se le concede a la información como instrumento consustancial de un — hasta hace poco- inédito «derecho a una Buena Administración» ${ }^{7}$. Esta configuración «cuasi constitucional» podría servir para superar las debilidades normativas que acompañan a un formato meramente principial, es decir, como indicador genérico que tendría que inspirar el funcionamiento de las entidades de derecho público. Una caracterización como derecho, aun cuando no comporte su inmediatez ni aplicabilidad directa sin previa mediación de legislador, favorece el carácter vinculante que tiene la configuración normativa de una obligación —esta vez sí que exigible en la esfera jurisdiccional— de suministrar y fijar las condiciones de acceso a la información para el ciudadano; a modo casi o de facto de un «derecho de prestación» que genera un crédito a favor de quien pretende obtener esa información de la Administración Pública. La información activa se puede concebir como un principio que, por un lado, genera para las instituciones públicas una serie de obligaciones en orden a garantizar la transparencia; y desde otro ángulo, otorga al ciudadano una «posición jurídica prestacional», en forma de derecho

6 Una evidencia clara del binomio transparencia/participación se puede localizar en la configuración que reciben en la Ley 19/2013, como principios esenciales que deben inspirar las funciones del Consejo de Transparencia y Buen Gobierno, el cual está obligado a articular «mecanismos de participación como vía de colaboración de los ciudadanos en el mejor desempeño de las funciones del organismo y para favorecer el cumplimiento de la normativa de transparencia y buen gobierno» (art. 6 c, del Real Decreto 919/2014, de 31 de octubre, por el que se aprueba el Estatuto del Consejo de Transparencia y Buen Gobierno.

7 Pese a que su potencial queda bastante devaluado a partir de la doctrina elaborada por el TC sobre la ineficacia directa de los derechos estatutarios como derechos subjetivos y accionables en el terreno jurisdiccional (SSTC 247/2007 y 31/2010), estos Estatutos dan un testimonio exacto de la importancia que tiene la información y el acceso a la información, como componentes estructurales del Derecho a la Buena Administración. Así, en el artículo 31 del Estatuto andaluz del 2007 indica expresamente que este derecho comprende el derecho a obtener una información veraz, (...) a acceder a los archivos y registros de las instituciones, corporaciones, órganos y organismos públicos de Andalucía, cualquiera que sea su soporte, con» las excepciones que la ley establezca». En términos bastante similares se pronuncia el artículo 30 del Estatuto catalán del 2006, aunque en este caso la Buena Administración forma parte del objetivo que pretende garantizar el acceso a los servicios públicos. 
subjetivo a exigir que esa información facilite el conocimiento del funcionamiento y actividad de esas mimas entidades y poderes públicos ${ }^{8}$.

\section{FORMULACIONES DE LA «INFORMACIÓN ACTIVA» DERIVADAS DE LA CONSTITUCIÓN}

El derecho a la información, entendida en su modalidad de información activa encuentra una cierta receptividad en el articulado de la CE. Ciertamente no ha sido enunciada de forma expresa, pero directa o implícitamente sí ha encontrado receptividad constitucional en varios preceptos y dimensiones institucionales.

En primer lugar, el artículo 9.3 consagra la publicidad de las normas, entre aquellas que podríamos considerar características y garantías cardinales que definen constitucionalmente el Estado de derecho. De esta forma, la divulgación pública del conjunto del ordenamiento, adquiere un sentido netamente prescriptivo que se proyecta sobre la globalidad de los órganos o instituciones públicas; todos tienen que actuar de emisores de una información que emana de sus respectivos canales de producción normativa.

En la esfera político-institucional la transparencia informativa aparece así mismo contemplada en el marco de la actividad parlamentaria de las Cortes generales. Se establece en este sentido la obligatoriedad de la publicidad, como regla general que debe aplicarse al desarrollo de del funcionamiento de las sesiones plenarias (art.80, $\mathrm{CE}$ ); las posibles excepciones a este principio tienen que superar el filtro de una mayoría cualificada, y siempre en las condiciones y límites señalados reglamentariamente en cada Cámara.

Pero sin duda es en la esfera jurisdiccional y administrativa donde el texto constitucional enfatiza con mayor intensidad la necesidad de garantizar la información por parte de los organismos públicos. En lo que respecta al Poder judicial, resultan significativos los indicadores constitucionales sobre la obligatoria publicidad de las actuaciones judiciales en el marco de los procesos jurisdiccionales (art. 24). Se trata de una garantía de naturaleza procesal —esta vez sí - con una virtualidad jurídica efectiva, ya que ha sido formulada como auténtico «derecho fundamental» al que se le aplican las máximas opciones de defensa y amparo constitucional. Por otro lado,

8 F. Rey considera además que ese derecho prestacional tiene un carácter político. La prestación podría tener un contenido sustancialmente «normativo»; es decir, se materializaría en la obligación «jurídica» de adaptar el ordenamiento, tal y como señala Cotino; o bien incluso «estructural», esto es, mediante la creación de procedimientos para el conocimiento y acceso público a la información, en consonancia con lo que recomienda Observación general n 34 del CDH de 2011. Vid. Y F.Rey, «Quod omnes tangit ab omnibus cognitum es-se debet: el derecho de acceso a la información pública como derecho fundamental», en Revista Jurídica de Castilla y León, núm., 33, 2014, p. 12 y ss. Y L.Cotino Hueso, «El reconocimiento y contenido internacional del acceso a la información pública como derecho fundamental», en Teoría y Realidad Constitucional, núm. 40, 2017, pp. 279-316 
esa misma publicidad se predica también, como principio general y mandato constitucional al conjunto de las «actuaciones judiciales» (art. 120); regla que únicamente puede ser excepcionada cuando así se haya dispuesto por las leyes que regulan los diferentes órdenes jurisdiccionales.

En la dimensión administrativa tiene lugar la enunciación más clara y directa del principio y obligación de la transparencia. Ésta cobra expresividad en varios planos materiales sobre los que se proyecta el procedimiento administrativo.

En primer lugar, la CE va a asegurar la existencia de un espacio donde se articule la participación ciudadana en los procedimientos de formación de normas administrativas. Mediante el «trámite de audiencia» (art. 105.a), tanto los particulares de forma individual, como las entidades que puedan tener algún interés legítimo en la elaboración y resultado de la norma reglamentaria, tienen garantizada la emisión de sus opiniones y posicionamiento jurídico. Del mismo modo, la CE mandata al legislador para diseñar fórmulas de «acceso» de los ciudadanos a los «archivos y registros administrativos» (art. 105.b). Un último método colaborativo se establece en la norma fundamental, referido esta vez al conjunto de los «actos administrativos», de nuevo mediante la implantación de una fase necesaria de «audiencia del interesado» (art. 105.c). En todo caso conviene ya anticipar que este derecho — de naturaleza constitucional, aunque no forme parte del Título Primero de la CE — tiene un alcance más limitado que el derecho general de información (en su doble versión de información activa y acceso a la información) diseñado en la Ley 19/2013. Su proyección es más reducida en lo referido tanto al sujeto titular (sólo interesados directos), a los soportes informativos sobre los que se tiene acceso (sólo archivos y registros administrativos) y a los sujetos obligados por el derecho constitucional (sólo Administración Pública, pero no las demás instituciones de naturaleza igualmente pública).

Si se examinan con una visión no puramente formalista se pueden reconocer en estas fórmulas de participación administrativa previstas en la norma constitucional unos efectos que en potencia superan los puramente consultivos o de simple trámite procesal. Su virtualidad jurídica sería nula en cuanto mecanismo que pueda condicionar de manera automática e inmediata el sentido de la norma o acto administrativos; ciertamente la audiencia no resulta determinante de la decisión final que adopte la Administración. Pero vista desde su posible «operatividad política» estos métodos de democratización administrativa pueden llegar a tener una potencialidad mucho mayor de la que se desprende de una lectura literal realizada sólo en clave jurídica. Creemos que esta dimensión «procesual» de la participación ciudadana en los asuntos públicos trasciende más allá de lo «consultivo», para afectar al ejercicio de la dirección política de las Administraciones Públicas. La medición tendría que llevarse a cabo sobre la capacidad que tienen las demandas procedentes de amplios grupos sociales, representativos de los llamados «intereses difusos», para influir en la toma de decisiones en torno a cuestiones de considerable repercusión en el conjunto de la sociedad. Frente al eventual coste político de resolver en forma contraria a la dirección que defienden aquellos intereses y colectivos, cobran un valor no sólo «metódico» o procedimental, 
sino también — podríamos adjetivarlo así- sustantivo; en especial si la «opinión social» o «colectiva» que se manifiesta en esa etapa del procedimiento resulta netamente antagónica a la oportunidad y sentido de la norma o acto administrativos.

\section{LA LEY 19/2013, DE 9 DE DICIEMBRE, DE TRANSPARENCIA, ACCESO A LA INFORMACIÓN PÚBLICA Y BUEN GOBIERNO. UNA REFORMA PARCIALMENTE INNOVADORA}

\subsection{Sobre la configuración legislativa del principio de trasparencia}

Frente al silencio (explícito) o la indeterminación constitucional, el legislador español aporta un concepto normativo bastante preciso de la transparencia. De una parte propone una configuración principial, que se concreta en un mandato u obligación dirigido a los poderes públicos. Concebida de esta manera, no puede predicarse de esta primera dimensión «activa» de la información una potencial exigibilidad en la esfera jurisdiccional; a diferencia del «acceso a la información» que sí se verá reforzado en la norma al ser diseñado en forma de «derecho legal». La transparencia actúa como principio de carácter instrumental enfocado a una serie de objetivos (la rendición de cuentas y la fiscalización de los recursos públicos) en los que se sintetiza la noción de control social de las estructuras organizativas y los actores que las lideran.

La Ley 19/2013 representa la respuesta positiva a la existencia de un clima social de progresiva desafección ciudadana hacia el modelo político en general, así como ante la incapacidad de las regulaciones normativas precedentes para solucionar eficazmente el problema — globalizado de manera transversal— de la corrupción política; una patología que afecta tanto al sistema de partidos, como a una parte significativa las instituciones políticas y administrativas.

El legislador pretende superar los notables déficits de que se detectan en la esfera legislativa en materia de publicidad activa. Supone por tanto el intento de profundizar y reforzar los niveles de publicidad, ampliando el espacio institucional sobre el que se proyectan e intensifican los mandatos de transparencia. Se pretenden cubrir aquellos ámbitos que quedaban al descubierto en los canales tradicionales de información pública, identificables dentro de la legislación general sobre el procedimiento administrativo. También de los que ya se habían implantado en algunas parcelas organizativas o esferas de funcionamiento de la Administración ${ }^{9}$ La Ley resultaba en con-

9 Como más indicativas cabe mencionar la Ley 27/2006, de 18 de julio, por la que se regulan los derechos de acceso a la información, de participación pública y de acceso a la justicia en materia de medio ambiente; la Ley 37/2007, de 16 de noviembre, sobre reutilización de la información del sector público; y la Ley 11/2007, de 22 de junio, de acceso electrónico de los ciudadanos a los servicios públicos, en la que se prevé el empleo de medios electrónicos para facilitar la participación, la transparencia y el acceso a la información. 
secuencia necesaria para complementar posibles lagunas jurídicas. Pero en realidad su utilidad principal y razón de ser hay que enmarcarla en un proceso de regeneración democrática; un proyecto de naturaleza política que ha sido en los últimos años uno de los grandes desafíos de la democracia española.

La información activa de naturaleza y contenido jurídicos ha sido vehiculada igualmente por la Ley 39/2015 (LRJPAC). Su artículo 83 prevé la apertura de un período de información pública por parte del órgano que resuelve un procedimiento administrativo. La articulación de esa fórmula de participación ciudadana viene descrita igualmente en la norma. Partiendo de la publicación en el Diario oficial_correspondiente, se permite a cualquier particular — persona física o jurídica (en este segundo supuesto se autoriza sólo a las organizaciones y asociaciones reconocidas por la ley)_ el examen del expediente, que debe ser puesto en conocimiento público en la sede electrónica del organismo. La divulgación se acompaña de la apertura de un plazo para posibilitar la presentación de alegaciones (20 días o más). El trámite de audiencia pública otorga a quien participa en él — sea o no en condición de interesado ${ }^{10}$ — un doble derecho; primero a expresar su opinión o posición jurídica mediante la formulación de alegaciones; y en segundo lugar el derecho a recibir de la Administración una «respuesta razonada». El sentido prescriptivo con que se enuncia ese derecho implica por consiguiente para esa misma Administración una obligación con doble contenido: el deber inexcusable de responder; y el de hacerlo además de forma expresamente motivada; esto es, con las razones que considere pertinentes al caso el órgano administrativo o poder público.

En una línea que podríamos considera análoga o paralela a la versión de la LRJ del 2015, Régimen Jurídico del Sector Público (Ley 40/2015) implanta de forma nítida un deber de transparencia al conjunto de Administraciones Públicas, conjuntamente en el mismo apartado en que se impone como principio genérico de su actuación «la participación» (art. 3). La trasparencia, junto a la publicidad y la accesibilidad, se marcan además como criterios de funcionamiento de las sedes electrónicas de organismos públicos (art.38). Las entidades públicas se hacen responsables por mandato legal, a través de las respectivas sedes electrónicas que se habiliten, del cumplimiento de una serie de condiciones señalizadas expresamente en el artículo 38 de la Ley 40/2015: integridad, veracidad y actualización de la información y los servicios $^{11}$.

10 Nos parece interesante destacar la salvedad prevista en el precepto legal, según la cual se delimita al titular de un interés legítimo del particular o persona jurídica que interviene simplemente en el procedimiento administrativo: «la comparecencia en el trámite de información pública no otorga, por sí misma, la condición de interesado».

11 Con un excesivo grado de indeterminación el precepto en cuestión parece apuntar a la creación de un sistema de «interlocución» entre Administración y administrado, que convierte en verdadera o participativa esta modalidad de información activa, al prever que «las sedes electrónicas dispondrán de sistemas que permitan el establecimiento de comunicaciones seguras siempre que sean necesarias. 
A propósito de aportaciones constructivas de la Ley 9/2013, cuenta entre las más significativas el carácter jurídico y no puramente deontológico de los compromisos que se adquieren en esta dimensión normativa. Pese a la elevada dosis de conceptualidad, es incuestionable el efecto vinculante que tienen las directrices que se han marcado legalmente. La medida de su eficacia jurídica se comprueba fácilmente por las consecuencias sancionatorias que conlleva su incumplimiento. Precisamente este carácter prescriptivo de sus disposiciones proporciona a la ley un potencial indudable como instrumento preventivo frente a fenómenos negativos tan sistémicos ya como la corrupción. La transparencia se configura en definitiva, no como un principio programático o un deber genérico de eficacia diferida, sino como un criterio general de funcionamiento del que deriva un catálogo de obligaciones jurídicas de aplicabilidad inmediata y directa exigibilidad.

En lo que respecta al ámbito subjetivo institucional, sobresale una aparente pretensión de exhaustividad en cuanto a las entidades que quedan sujetas a las obligaciones de transparencia e información. En efecto, no faltan en el artículo 2 de la Ley posiblemente ninguna que forme parte o pueda tener alguna relación con las instituciones públicas. Con esa orientación expansiva ${ }^{12}$ y en el intento de evitar espacios al descubierto de los mandatos legales, se incluyen también a todas aquellas entidades privadas que sean financiadas parcialmente con fondos públicos; siempre que superen determinadas cuantías fijadas legalmente (más de 100.00 euros o al menos el $40 \%$ del conjunto de lo que ingresen). Quedan además dentro del perímetro de proyección los partidos políticos, al igual que las organizaciones sindicales y empresariales.

En lo que respecta específicamente a las formaciones políticas no cabe negar, como constatación normativa, que la transparencia ha sido uno de los ejes centrales de las recientes propuestas legislativas para mejorar su modelo de financiación ${ }^{13}$. Concretamente en materia de «publicidad activa» la Ley Orgánica 3/2015, de 30 de marzo, de control de la actividad económico-financiera de los Partidos Políticos, impone a los partidos la obligación de publicar en su página web toda información relativa a su financiación y actividades económico-financieras, así como el informe de fiscalización que se emite anualmente sobre aquéllas ${ }^{14}$. Con un grado similar de exi-

12 Sobre la repercusión expansiva del derecho a la información, tanto conceptualmente como en su proyección institucional, vid. O. Mir Puigpelat, «El acceso a la información pública en la legislación española de transparencia: crónica de un cambio de paradigma», en Revista Catalana de Dret Públic, núm. 55,2017 , pp. 48 y ss.

13 Vid. El análisis que he realizado sobre este tema en «El control sobre la financiación de los partidos políticos un desafío permanente para el legislador», Teoría y realidad constitucional, núm. 35, 2015, pp. 281-308.

14 El artículo 14.8 recoge establece un catálogo de datos de esta naturaleza que deben ser publicadas en la web del partido, a través de los cuales se puede tener una información precisa sobre la situación financiera de los partidos. El texto del precepto señala literalmente: «Los partidos políticos deberán publicar en su página web, en el plazo máximo de un mes desde la fecha de envío al Tribunal de Cuentas, el balance, la cuenta de resultados y en particular: la cuantía de los créditos pendientes de amortización, con especificación de la entidad concedente, el importe otorgado, el tipo de interés y el plazo de amortización, las subvenciones recibidas y las 
gencia en lo referido a transparencia informativa, las fundaciones vinculadas a los partidos políticos tendrán que divulgar en sus webs las aportaciones y donaciones que reciban.

\subsection{La Publicidad «activa» como dimensión instrumental del principio legal de Transparencia}

La transparencia se garantiza y perfila en primer lugar como una exigencia de carácter general para las entidades que entran de su ámbito de proyección, de publicar periódicamente y actualizar toda aquella información sobre «su actividad relacionada con la actividad y control de la actuación pública». El diseño legislativo impone dos notas más a la denominada «información activa»: gratuidad y accesibilidad (art. 5) ${ }^{15}$. Este elenco de prescripciones legales queda delimitado, no obstante, por un adjetivo (información) «relevante»—, que admite márgenes de interpretación demasiado laxos a la Administración.

Los principios generales que señala la Ley 19/2013 se conciben en realidad como un conjunto de condiciones mínimas que deben ser garantizadas por el conjunto de los organismos públicos del Estado. Su carácter «básico» ${ }^{16}$ además no obsta para reconocer a las Comunidades Autónomas (CCAA) una potestad de especificación y desarrollo de aquéllos en su ámbito institucional (art. 5.2) ${ }^{17}$.

donaciones y legados de importe superior a 50.000 euros con referencia concreta a la identidad del donante o legatario, sin perjuicio de lo establecido en el artículo 7.5 de la L.O. 2/1982, de 12 de mayo, del Tribunal de Cuentas».

15 La accesibilidad se utilizaría como un principio en virtud del cual los poderes públicos tendrían que garantizar la comprensión de los contenidos que conforman esa información institucional; no sólo al conjunto de los ciudadanos, sino de igual modo — mediante «medios o en formatos adecuados»— también a aquellos colectivos que sufren algún tipo de discapacidad (párrafo 5).

16 La Ley 19/2013 tiene carácter de normativa básica, dictada por el Estado en ejercicio de aquellas competencias exclusivas que le otorga la CE directamente relacionadas con el Régimen Jurídico de las Administraciones Públicas (art. 149.1.18) y la dimensión territorial de la igualdad (art.149.1.1).

17 Como modelo de referencia de una tendencia legislativa generalizada entre las CCAA —a veces incluso con anterioridad a la propia ley estatal - y para constatar la proyección e importancia que la transparencia informativa está teniendo en la esfera autonómica, se pueden señalar las principales normas y leyes que ha aprobado en esta materia la Comunidad Autónoma de Andalucía. Así, en la Ley 9/2007, de 22 de octubre, de la Administración de la Junta de Andalucía, se enunciaba ya la transparencia como un principio general de organización y funcionamiento, y derecho de la ciudadanía ante la actuación administrativa. En su dimensión local, La Ley 5/2010, de 11 de junio, de Autonomía Local de Andalucía, otorga a la transparencia el carácter de principio informador de los servicios locales de interés general, del que derivan obligaciones específicas de publicidad activa. Por último, va ser objeto de una regulación general en la Ley 1/2014, de 24 de junio, de Transparencia Pública de Andalucía.

A propósito de la legislación autonómica sobre Transparencia, se podrían citar las siguientes normas: Ley 4/2006, de 30 de julio, de transparencia y buenas prácticas en la Administración pública (Galicia), Ley 4/2011, de 31 de marzo, de la buena administración y del buen gobierno (Illes Balears), Ley Foral 11/2012, de 21 de junio, de Transparencia y del Gobierno Abierto (Navarra). Ley 4/2013, de 21 de mayo, de Gobierno Abierto (Extremadura, Ley 3/2014, de 11 de septiembre, de Transparencia y Buen Gobierno (La Rioja), Ley 12/2014, de 16 de diciembre, de Transparencia y Participación 
En el análisis de los principios generales de esta modalidad de información conviene recordar la existencia de algunos límites que pueden condicionar de manera restrictiva tanto el derecho como la obligación de transparencia (art. 5.3). La legitimidad de estas limitaciones viene marcada por la tutela de otro derecho fundamental — la protección de datos personales (art. 18.4, CE) — que tiene generalmente un efecto modulador sobre el alcance de todos los derechos que suponen el conocimiento público de informaciones sensibles o que puedan perjudicar otros bienes jurídicos con relieve constitucional (integridad moral, intimidad) ${ }^{18}$.

Finalmente, el legislador ha querido señalizar la metodología esencial con la que se pretende implementar las previsiones legislativas en materia de información activa. El instrumento principal serán sedes electrónicas o páginas web de cada institución u organismo público ${ }^{19}$. En todo caso, la técnica que se utilice debe asegurar unos objetivos que han sido precisados igualmente en la Ley: accesibilidad, la interoperabilidad, la calidad y la reutilización (art. 5. 4).

La Ley desglosa en varios bloques los contenidos principales de la información activa que han de garantizarse por el conjunto de Administraciones Públicas. El primero de ellos comprende la información que cabría adjetivar como puramente «institucional», referida fundamentalmente a datos relativos a la estructura organizativa, las competencias o funciones, la normativa de aplicación orgánica y el organigrama con los responsables públicos. La información anterior se complementa con la divulgación de los planes y programas anuales, así como las actividades, medios y temporalidad en la ejecución de estos últimos ${ }^{20}$.

Ciudadana de la Región (Murcia), Ley 12/2014, de 26 de diciembre, de Transparencia y Acceso a la Información Pública (Canarias), Ley 19/2014, de 29 de diciembre, de Transparencia, Acceso a la Información Pública y Buen Gobierno (Cataluña), Ley 3/2015, de 4 de marzo, de Transparencia y Participación Ciudadana (Castilla y León), Ley 8/2015, de 25 de marzo, de Transparencia de la Actividad Pública y Participación Ciudadana (Aragón), y Ley 2/2015, de 2 de abril, Transparencia, Buen Gobierno y Participación Ciudadana (Comunitat Valenciana). Sobre esta última destacaríamos el trabajo, Comentarios a la Ley 2/2015, de 2 de abril, de Transparencia, Buen Gobierno y Participación Ciudadana de la Comunitat Valenciana (Eds. Juan José DÍEZ SÁNCHEZ y Ricardo GARCÍA MACHO), Madrid, Editorial Reus, 2019,

18 Sobre el imprescindible equilibrio que debe alcanzarse entre las distintas versiones del derecho de información (publicación y acceso) y el derecho fundamental a la protección de datos, tal y como ha sido regulado en el Reglamento de la UE 2016/679, vid. A. Troncoso Reigada, «Los límites al acceso a la información: la protección de datos personales» en Informática y derecho, Revista Iberoamericana de Derecho Informático, núm. 1, 2016, pp. 47 y ss.

19 La ley ha previsto que esta informatización se canalice a través del llamado Portal de la Transparencia, enmarcado orgánicamente en el Ministerio de la Presidencia y cuya finalidad esencial es facilitar el acceso de los ciudadanos la información institucional de todas las entidades de la Administración General del Estado. No obstante, este tipo de plataformas informativas han sido «replicadas» en numerosos organismos públicos de otras Administraciones Públicas (autonómicas, provinciales, municipales) con notables mimetismos en cuanto al modelo, morfología y contenidos.

20 La información institucional no se limita sólo a la exposición de estos instrumentos de planificación, básicos para conocer el modo y forma en que se ejercen las funciones institucionales que ha sido atribuidas, sino que alcanza también a su implementación: «Su grado de cumplimiento y resultados 
La Ley engloba como parte de la información activa un segundo bloque de información de «relevancia jurídica» sobre del funcionamiento de los organismos públicos. Se desarrolla primero en una serie de ítems que permiten acceder a proyectos normativos que emana de los propios órganos de la Administración e instituciones con potestades legislativas (Gobierno, Parlamento), entre los que se mencionan los Anteproyectos de Ley y los proyectos de Decretos Legislativos; además de la que se contenga en memorias e informes de todos los proyectos normativos en los que interviene el órgano o institución.

Esta especie de apertura democrática no aporta una novedad significativa a los sistemas de comunicación oficial que ya existen en las instituciones de representación política estatales y autonómicas, con las que se puede conocer el proceso de elaboración de aquellas normas que, por su carácter y rango legislativo, deben pasar por la aprobación o convalidación parlamentaria. Quizás el auténtico open government resulta reconocible más claramente en algunos canales de participación que han sido diseñados en el nivel subestatal dentro de cierto número de instituciones legislativas. De manera similar a lo que sucede en la esfera administrativa, algunos Parlamentos autonómicos han establecidos mecanismo de audiencia ciudadana en alguno de los estadios del procedimiento legislativo. Estamos en presencia así de una modalidad de información autentica y doblemente activa. No sólo por lo que implica de conocimiento de asuntos y documentos de «relevancia jurídica»; sino por el hecho también de articular un instrumento de colaboración «activa» para el conjunto de la ciudadanía en los procesos de producción normativa que tienen lugar en sede parlamentaria ${ }^{21}$.

El apartado incluye la divulgación de todos aquellos documentos que puedan tener un contenido netamente jurídico, tales como «directrices, instrucciones, acuerdos, circulares o respuestas a consultas planteadas por los particulares u otros órganos». Y se completa con todos aquellos «documentos» que son sometidos a audiencia de los interesados y ciudadanos («información pública») durante la tramitación del procedimiento administrativo.

deberán ser objeto de evaluación y publicación periódica junto con los indicadores de medida y valoración, en la forma en que se determine por cada Administración competente. En el ámbito de la Administración General del Estado corresponde a las inspecciones generales de servicios la evaluación del cumplimiento de estos planes y programas»

21 Apuntemos como botones de muestra más representativos el caso de Extremadura y de Andalucía. La diferencia entre una y otras estriba en que en la primera esa audiencia se ha previsto antes de que se haya iniciado el iter legislativo del Anteproyecto de Ley, mientras en el Parlamento andaluz tiene lugar una vez se ha puesto en marcha ya el procedimiento legislativo, una vez adquirida por tanto la condición de proyecto de ley. En la Comunidad Autónoma de Andalucía las vías participativas y de información se han ampliado incluso a los mecanismos de control parlamentario, a través de las preguntas «de iniciativa ciudadana», que se pueden formular a los miembros del Gobierno autonómico, tanto a nivel individual o como de personas jurídicas. No obstante, esta posibilidad de acceso a la institución no es directa, ya que en realidad sólo se materializa sólo cuando un parlamentario acepta o ·asume» la formulación de la pregunta presentada por el ciudadano (artículo 165). 
Un tercer bloque de contenidos que componen la noción de la información activa afectan a un ámbito material imprescindible sin duda para la finalidad que se ha propuesto el legislador; que no es otro que favorecer la regeneración democrática como medio para frenar el nivel excesivo y sistémico de corrupción. En este sentido el artículo 8 de la Ley da cuenta implícitamente de que la transparencia informativa debe alcanzar también, en su calidad de mecanismo preventivo contra aquélla, a la divulgación de todos los actos administrativos que tengan una repercusión económica 0 presupuestaria. Para perfilar este tercer ámbito material de la información activa se propone un verdadero inventario con vocación de exhaustividad, que engloba aquellos supuestos que conllevan algún tipo de gasto o uso de recursos públicos: convenios, subvenciones y ayudas, presupuestos, cuentas anuales, informes de auditorías, retribuciones de altos cargos y responsables de entidades afectadas por la obligación de transparencia ${ }^{22}$.

\subsection{La garantía de las obligaciones de información activa: el Consejo de Transparencia y Buen Gobierno}

Una de las aportaciones más novedosas de la Ley 19/2013 es la creación del Consejo de Transparencia. Este organismo se erige en el instrumento decisivo para dar credibilidad y asegurar el cumplimiento del catálogo de indicaciones legales sobre información activa, el derecho de acceso a la información pública, y la correcta observancia de las normas sobre buen gobierno ${ }^{23}$.

En la tarea preferente que le corresponde, el Consejo focaliza en exclusiva la función de control en la Administración del Estado. Esta delimitación restrictiva del espacio institucional sobre el que se proyecta la competencia básica y fundamental que se le ha encomendado representa un elemento negativo del diseño confeccionado por el legislador estatal. Fuerza a las otras Administraciones — principalmente las autonómicas - a establecer mecanismos alternativos o similares para hacer cumplir unos mandamientos legales que se dirigen, con la misma intensidad y efectos vinculantes, al conjunto de organismos de derecho público.

Del mismo modo, también quedan fuera de su esfera funcional a los partidos políticos, organizaciones que ciertamente no ostentan la condición de entidades de derecho público, y para los que no se contempla — al menos en esta norma— la apli-

22 Sin ánimo de analizar ahora en profundidad todos y cada uno de esas actuaciones, resoluciones o disposiciones sobre las que recae la obligación de suministrar información, al menos es necesario subrayar que no se agotan en ellas todos los ámbitos económicos sobre los que deberían dar cuenta las Administraciones. Para reconocer los déficits en este ámbito material,

23 En el Preámbulo se menciona además otra competencia que tiene mucho que ver con la función que inspira en buena medida al conjunto de la norma legislativa: la promoción de la cultura de transparencia en la actividad de la Administración Pública. No cabe minusvalorar la importancia de este cometido como método preventivo para conseguir resultados positivos en la lucha contra la corrupción, sin duda uno de los objetivos que inspiran la Ley 19/2013. 
cación de esta fórmula de garantía en el cumplimiento del deber de transparencia. El hecho de quedar fuera de la proyección del régimen sancionatorio que se impone a infracciones previstas en esta norma, viene a devaluar la eficacia real de las obligaciones legales de información activa.

El ejercicio de la función de control del Consejo de Transparencia se concreta y despliega a través de resoluciones que tienen un alcance superior al meramente declarativo; en la medida, primero, en que comprenden medidas concretas para hacer frente al incumplimiento, y al mismo tiempo pueden conllevar actuaciones disciplinarias. Por otro lado, dentro del régimen sancionador previsto se configura como «grave» el incumplimiento reiterado de las obligaciones de publicidad, una infracción que comporta automáticamente la aplicación de aquellas medias disciplinarias que correspondan según la normativa administrativa.

El Consejo de Transparencia y Buen Gobierno se presenta como un órgano de naturaleza administrativa con facultad para ejercitar una función «prejudicial» de control. No cuenta por tanto con potestad para imponer resoluciones o decisiones a las entidades públicas (o privadas) sometidas a la evaluación de cumplimiento de la ley. Por otro lado, esa función de control representaría en cierto modo una alternativa a los recursos administrativos.

No se encuentra subordinado al poder político, al estar dotado por expreso reconocimiento legal de «autonomía y plena independencia» (art. 33) para el cumplimiento de sus fines y el ejercicio de sus competencias. Aunque en el Preámbulo de la Ley se viene a sostener que aquellas características de la institución tienen su fundamento en la modalidad escogida para el nombramiento de su Presidente, no nos parece que sea precisamente la fórmula de designación parlamentaria una garantía efectiva de su independencia real. No obstante es necesario subrayar la voluntad del legislador por asegurar la autonomía del Consejo, cuando se imponen una serie de exigencias teóricamente rigurosas en la selección del responsable de la institución: una duración del mandato superior a la de legislatura parlamentaria (cinco años), la calidad profesional del candidato, su comparecencia en la Comisión correspondiente del Congreso de los Diputados, y la aprobación de la propuesta por una mayoría cualificada (absoluta) ${ }^{24}$. La experiencia que se tiene ya sobre la «politización» que se produce en los procesos de designación de otras instituciones constitucionales (Consejo General del Poder Judicial, Tribunal Constitucional) —donde además se requiere una mayoría cualificada superior - pone en evidencia que la intervención de las Cámaras Legislativas nunca ha sido hasta el momento sinónimo de neutralidad política. Tampoco favorece a esta última el criterio instaurado en la Ley para determinar el órgano colegiado interno sobre el que recaen las principales facultades del Consejo. Efectivamente, si

24 El método de designación ha sido regulado por el artículo 37 de la Ley se encuentra condicionado en principio por el origen gubernamental de la propuesta de designación (el titular del Ministerio de Hacienda y Administraciones Públicas); parece incluso que este protagonismo del Ejecutivo queda al descubierto en la letra del precepto, que se refiere a «refrendar» al candidato propuesto, y al plazo taxativo de tiempo para hacerlo (un mes). 
se observa la condición política e institucional de la mayoría de sus miembros no cabe concluir de forma muy optimista sobre un funcionamiento plenamente libre de influencias externas del Consejo ${ }^{25}$. En todo caso, creemos que por el momento no se disponen de datos para comprobar la funcionalidad y eficacia que puede llegar a tener este organismo en el futuro ${ }^{26}$.

\subsection{Los Ombudsman y el control de la transparencia}

La figura del Ombudsman, en sus diferentes versiones (nacional, autonómicos, locales e institucionales), puede llegar a ser un instrumento útil para asegurar el cumplimiento de las obligaciones sobre transparencia e información. En su faceta - y seña de identidad funcional — como Comisionado parlamentario encargado de controlar la actuación de las entidades públicas, se encuentra en una posición privilegiada para reconocer los déficits que se producen a la hora de implementar en el plano

25 Una simple observación sobre el diseño legislativo (art. 36) de la composición de la Comisión de Transparencia y Buen Gobierno, no ofrece demasiadas dudas sobre la presencia y mayoría de representantes directamente políticos (Diputado, Senador, Secretaría de Estado de Administraciones Públicas) o institucionales, con dependencia gubernamental en el proceso de nombramiento (Tribunal de Cuentas, Agencia Española de Protección de Datos); se salvaría no obstante de potenciales influencias políticas la presencia de un representante del Defensor del Pueblo.

26 Se cuenta ya no obstante con alguna información indicativa sobre algunos déficits que podrían mejorar esos parámetros. Contenida en primer lugar, en la Resolución de 14 de febrero de 2018, del Consejo de Transparencia y Buen Gobierno, por la que se publica el resumen de la Memoria de cumplimiento de la Ley de Transparencia, Acceso a la Información Pública y Buen Gobierno y de actividades del Consejo durante el ejercicio 2016. En este documento se aconsejaba excluir del ámbito subjetivo de la evaluación a los sujetos mencionados en el artículo 3 de la Ley; esto es, a los «sujetos de derecho privado» (partidos políticos, organizaciones sindicales y empresariales), además de a las entidades privadas afectadas por los límites legales de financiación pública ( percepción en un año de ayudas o subvenciones públicas en una cuantía superior a 100.000 euros o cuando al menos el $40 \%$ del total de sus ingresos anuales tengan carácter de ayuda o subvención pública). El Informe justifica esta exclusión del ámbito de la evaluación por una serie de factores, entre los que se señalan: el número excesivo de sujetos que engloba esta categoría, la ausencia de un censo oficial o información fiable que permita identificarlas, así como la laguna reglamentaria que existe a la hora aplicar correctamente las disposiciones legales. En el Informe de evaluación del cumplimiento de la Ley de transparencia del 2017 se extraen algunas conclusiones de interés. Como por ejemplo, que el índice de cumplimiento de información obligatoria del Portal de Transparencia es de 6,41 puntos (sobre una escala de 0 a 10); y de 5,73 puntos en cuanto a datos e informaciones de publicación voluntaria. Se viene a subrayar también las posibilidades de mejorar la estructura y organización de los contenidos informativos y solucionar ciertas lagunas informativas. Reconoce dificultades para la localización de datos o informaciones obligatorias. Desde el punto de vista de los contenidos, advierte de que falta información sobre contratos adjudicados directamente en la categoría de información económica y presupuestaria; además de que sería recomendable mejorar su comprensibilidad. Propone finalmente en el Portal denominado «Transparencia voluntaria» o "Información de relevancia del art. 5 de la ley» un apartado específico con datos o informaciones específicos y no contemplados en otros apartados de la ley; procesos de participación pública en la elaboración normativa, Relaciones de Puestos de Trabajo, información sobre CCAA, Información sobre entes públicos, estadísticas de interés, más información presupuestaria, etc. 
administrativo los objetivos y mandamientos legales. La competencia del Defensor para realizar una labor de fiscalización en este ámbito tiene su base en la configuración de la transparencia como principio de naturaleza «prescriptiva», que tiene su base en la misma Constitución (art. 105) y la legislación sectorial (estatal y autonómicas).

Aunque podría considerarse como órgano «inespecífico» de control de la transparencia pública, la figura del Ombudsman ejerce un papel de garante institucional de todos aquellos derechos que dispongan de una configuración jurídica (constitucional, legal, reglamentaria). Entre ese amplio catálogo de naturaleza tan heterogénea se incluyen el derecho de información en sus distintas modalidades (información activa y derecho de acceso a la información). Esta dimensión específica y complementaria del control que realizan los Omdusperson cuenta con distintas modalidades de ejecución: Comisión Adscrita al Defensor autonómico (Castilla y León), competencia compartida entre Valedor do Pobo y Comisión de Transparencia, presentación de quejas indistintamente a Defensor o Consejo de Transparencia, o como procedimiento de evaluación externa de la ley (Sindic, Cataluña) ${ }^{27}$.

La intervención del Ombudsman evita la judicialización de las controversias que genera la aplicación de los mandatos sobre transparencia e información. Se trata de una ventaja sin duda cuando, además, la labor de fiscalización se ejerce de manera neutral y desde el criterio siempre de la autonomía funcional. En este caso su competencia se proyecta precisamente sobre la actuación y decisiones que adopten el organismo creado para hacer cumplir aquellas obligaciones. De este modo, se está implementando un mecanismo de doble fiscalización que puede garantizar la eficacia y cumplimiento de las previsiones legales ${ }^{28}$. No obstante, cabe dudar razonablemente de la necesidad de implantar esta duplicidad de mecanismos de control (administrativa y de persuasión). Es necesario recordar en este punto que la función «propia» de cualquier figura de Ombudsman no es dictar resoluciones vinculantes o imponer de sanciones, sino elevar recomendaciones y sugerencias. Las primeras representan una

27 Vid. Sobre la función que pueden desempeñar los defensores autonómicos en la supervisión del cumplimiento de las obligaciones de transparencia, Fernández Rodríguez ha constatado un aumento apreciable de quejas que, desde la aprobación de la Ley 19/2013, se están presentado ante los Omdudsman autonómicos relativas problemas que generan las Administraciones en el acceso a la información pública; en los informes se pone de relieve que hay ámbitos específicos donde ese incremento es significativo, como la protección del medio ambiente o la Administración local, los déficits son significativos vid. J.J. Fernández Rodríguez, «El papel de las defensorías del pueblo en España en el control de la transparencia y el acceso a la información», en Revista Estado, Gobierno y Gestión Pública, núm. 27, 2016. pp. 89 - 116

28 En el terreno de los resultados, los informes que se conocen tras la aprobación de la Ley ponen de relieve un aumento de quejas a los Ombudsmen sobre déficits de transparencia. La Administración municipal es el ámbito institucional donde se detecta el mayor número de quejas; referidas especialmente al acceso a la información, derivadas de derechos constitucionales, como consecuencia del ejercicio de un cargo de representación política; o información medioambiental, como supervisión del cumplimiento Ley del 2005. 
potestas propia de los órganos administrativos; las segundas encajan en su estatus funcional en la medida en que son la expresión de una auctoritas sin capacidad resolutiva.

\section{EL DEBER DE TRANSPARENCIA INFORMATIVA EN LA ESFERA DEL PODER JUDICIAL}

La Administración de Justicia constituye uno de los ámbitos institucionales del Estado donde la implementación del principio de transparencia encuentra ciertas especialidades, cuando no dificultades para hacerse efectivo ${ }^{29}$. La existencia de disposiciones jurídicas y la programación de métodos para romper con la imagen de opacidad que ha tenido históricamente el Poder Judicial, no arroja todavía unos resultados demasiados tangibles. La razón estriba posiblemente en el hecho de que la naturaleza de la actividad jurisdiccional en sí misma requiere una modulación del alcance de las obligaciones que comporta la transparencia informativa. No obstante, los pasos que se están dando para ampliar el acceso a la información judicial y los datos que se ofrecen como información institucional «activa» ponen de relieve la importancia de la visibilidad de los actos procesales y las resoluciones judiciales ${ }^{30}$; no sólo para asegurar la efectividad de los principios fundamentales de imparcialidad e independencia judicial, sino incluso también asegurar el cumplimiento de garantías esenciales en determinados procedimientos jurisdiccionales ${ }^{31}$.

29 Para conocer el impacto en la jurisprudencia de la aplicación de la normativa sobre transparencia y buena administración se puede ver en J. Ponce, «Los jueces, el derecho a una buena administración y las leyes de transparencia y buen gobierno», en Administración al día, INAP, 19/1/2017. Para el autor, los jueces «están realizando una labor de precisión del derecho, delimitando, poco a poco, su alcance y utilidad en la limitación y guía de la actuación administrativa»; especialmente — subraya tambiéngracias a su aplicación jurisdiccional (TEDH, TJUE, Tribunal Supremo) se está afianzando el carácter obligacional de las normas legales sobre transparencia entre sus destinatarios y responsables públicos.

30 En cuanto a las sentencias, la LOPJ (art. 235 bis, 266) modula el alcance de la publicidad de este tipo de resoluciones judiciales, estableciendo algunas limitaciones (total o parciales al texto), justificadas por la necesidad de garantizar otros derechos (intimidad), el anonimato de víctimas o perjudicados, el respeto a personas que requieren una tutela especial, o en la medida en que puedan afectar también a datos de carácter personal.

31 Sin duda, la grabación audiovisual que se lleva a cabo de la fase oral de los procesos judiciales conforma una modalidad de información activa, a través de la cual se puede conocer y comprobar si la actuación del órgano judicial se ha ajustado a las reglas del procedimiento y, en consecuencia, se han respetado las garantías procesales de las partes en las que se condensa el derecho fundamental a la tutela judicial (art. $24 \mathrm{CE}$ ). Como caso más paradigmático y de actualidad, la divulgación completa de todas las sesiones que se han celebrado del juicio sobre Procés ha permitido a la opinión pública disponer de un conocimiento directo e inmediato sobre el desarrollo del que probablemente ha sido el proceso judicial penal más importante desde la implantación de la democracia constitucional española. Finalmente, hay que recordar que la publicidad es un imperativo legal inexcusable, cuyo incumplimiento puede dar lugar a la declaración de nulidad del proceso, de acuerdo con los señalado en el artículo 680 de la Ley de Enjuiciamiento Criminal («los debates del juicio oral serán públicos, bajo pena de nulidad»); un 
En la esfera internacional una propuesta indicativa de esta sensibilidad en favor de la transparencia y la información está contenida en las Recomendaciones en materia de transparencia, rendición de cuentas e integridad de los sistemas de justicia iberoamericanos, consensuada en la XVI Cumbre Iberoamericana de poder Judiciales (2012). Aparecen en este documento un catálogo de indicaciones que, pese a no tener un valor normativo ni automáticamente vinculante, permite conocer los métodos que darían cumplimiento a una obligación que se está marcando ya en la esfera legal. En todo caso, merece una especial consideración el enfoque central del documento donde se conecta directamente la transparencia con los que serían, al mismo tiempo, su presupuesto y objetivo fundamentales. En efecto, la finalidad de convertir la transparencia en uno de los principios fundamentales de la actuación de los poderes públicos, cobra sentido a través de las técnicas con las que se implemente y garantiza la responsabilidad (rendición de cuentas) y se asumen como propios los valores de la ética pública.

La iniciativa no renuncia a proporcionar una visión propia sobre las categorías conceptuales en los que se desglosa la noción de transparencia: activa, pasiva, externa e interna. En concreto, y referido especialmente a su dimensión «activa», considera necesario suministrar al público a través de los medios electrónicos que se pongan a su servicio ${ }^{32}$, la información sobre los órganos e integrantes del Poder Judicial y a los denominados genéricamente como Consejos de la Magistratura, en forma completa, actualizada y con fácil acceso, sin mediar requerimiento alguno.

En sentido pasivo, la transparencia se entendería — en el documento aprobado por los representantes de los Poder Judiciales - como el derecho de los interesados (personas físicas y jurídicas) a solicitar, ceder y recibir la información que obre en poder de estos órganos públicos. La recomendación enfatiza además que el ejercicio de este derecho conlleva una obligación de proporcionar esa información solicitada. El acceso a la información se debería articular — señala el documento - mediante un procedimiento administrativo adecuado que contemple acciones de reclamo ante la entrega indebida de información o su rechazo infundado.

El documento no se circunscribe a la dimensión conceptual, sino que enuncia un abanico de mecanismos y medidas específicas que contribuyen a garantizar el objetivo de la transparencia en el seno de la Administración de Justicia de los países signatarios del acuerdo: sustitución de soportes físicos, Oficinas de información, Gabinetes de prensa o vocerías, Sitios electrónicos. Y junto a los anteriores elementos estructurales, algunos de los principios que refuerzan aquélla en el funcionamiento de los órganos

mandato desde el cual se ampara la libertad informativa de los medios de comunicación, que cuentan por tanto con el derecho de acceder a las vistas orales, tal y como ha señalado reiteradamente el TC.

32 En este sentido, el Acuerdo de la Cumbre Judicial va a subrayar que la promoción por los Poderes Judiciales iberoamericanos de las diferentes modalidades en las que se concreta el principio de trasparencia (activa, pasiva, interna y externa), se debe materializar «predominantemente a través de los medios tecnológicos disponibles comprendiendo la información relevante del funcionamiento del sistema judicial y de sus integrantes, de manera oportuna y constantemente actualizada». 
judiciales y el ejercicio de su potestad jurisdiccional: Protección de datos sensibles, oralidad y publicidad de los actos procesales, Motivación y claridad de las decisiones.

Las propuestas se ultiman y complementan una metodología que pretende mejorar los sistemas de información y los contenidos que el ciudadano tiene derecho a conocer: Información presupuestaria, Alcance de la información suministrada en las áreas de gestión y administración, Políticas de atención al usuario, publicidad de las estadísticas sobre indicadores y grado de satisfacción de los usuarios en relación con el servicio público de la Justicia, así como las acciones institucionales emprendidas para la mejora del servicio.

La transparencia como principio general del funcionamiento de las instituciones públicas tiene necesariamente unas particularidades significativas en lo que respecta al Poder Judicial. De este modo, la Ley Orgánica del Poder Judicial (LOPJ) impone algunos límites y establece ciertas prohibiciones que delimitan y restringen el alcance de su adaptación al ejercicio de la potestad jurisdiccional ${ }^{33}$. En efecto, la obligación de garantizar el secreto profesional en las actuaciones judiciales implica ya una restricción evidente y lógica a la aplicación del principio de transparencia en esta función primaria de la justicia. En este orden y con esta finalidad, el artículo 61 legitima este criterio de excepcionalidad en base al respeto necesario de los derechos de las partes, y frente a un potencial «uso indebido» del juez de las informaciones que se obtienen normalmente sobre datos y hechos que se hayan puesto en su conocimiento durante el proceso judicial en tramitación. Este deber de reserva es absoluta, alcanzando a las deliberaciones previas a la adopción de la resolución judicial. Pero las restricciones al conocimiento público que se producen en una parte del procedimiento jurisdiccional no impiden que se tenga que asegurar al mismo tiempo la publicidad en otras fases del mismo. Favorece la información la adopción del principio de oralidad o el hecho de que las sesiones que se celebran de los juicios sean públicas como regla general. Parece por tanto que la LOPJ ha querido encontrar - y así lo indica expresamente en su artículo 63- un equilibrio entre el secreto profesional y el principio de transparencia.

A este objetivo apunta también otro mecanismo prediseñado por la LOPJ, y más tarde desarrollado por el Plan de Transparencia Judicial ${ }^{34}$. La Estadística Judicial

33 La limitación que tiene una proyección más relevante en el orden penal se enuncia en el artículo 301 de la Ley de Enjuiciamiento Criminal («las diligencias del sumario serán secretas hasta que se abra el juicio oral»). Sin embargo, la doctrina del TC ha venido a modular su teórica proyección sobre el conjunto de actos y trámites que componen el proceso penal. Así, en la Sentencia 13/1985 estableció ya algunas restricciones o matizaciones a esta regla general, incompatible con la mínima trasparencia informativa, declarando que no se pueden vetar a la libertad de información pública «algunos elementos de la realidad social» — siempre que no entren en contradicción con otros derechos fundamentales — aunque formen parte de la fase de instrucción del proceso. Esta interpretación ponderativa de la jurisprudencia constitucional avala la facultad para recibir información, a través de las Oficinas de Comunicación, sobre resoluciones procesales y datos que figuran en los autos, así como sobre el auto de apertura del juicio oral.

34 Resolución de 28 de octubre de 2005, de la Secretaría de Estado de Justicia, por la que se dispone la publicación del Acuerdo de Consejo de Ministros de 21 de octubre de 2005. 
constituye un instrumento plurifuncional que sirve no solo para objetivos como la planificación, desarrollo y ejecución de las políticas públicas en materia de Justicia, y en especial de aquéllas que orientadas principalmente a la modernización, la planificación y la gestión de recursos humanos y materiales de la Administración de Justicia (art. 461). Igualmente tiene una misión sustancial —enmarcada dentro del Plan - asegurar la disponibilidad de toda la información actualizada, incluyendo datos estadísticos, sobre asuntos y actividad que realizan todos los órganos y servicios que engloban el Poder Judicial. Los destinatarios de esta información, que se ha proporcionar de manera permanente y en condiciones de igualdad, serían el conjunto de instituciones que tienen algún tipo de competencia o relación con la Administración de Justicia (Cortes Generales, Gobierno, Comunidades Autónomas, Consejo General del Poder Judicial y Fiscalía General del Estado). El «pleno acceso» a los datos suministrados por la «estadística judicial» se garantiza asimismo a los ciudadanos, siempre de acuerdo con los medios electrónicos que se determinen reglamentariamente.

El primer paso para implantar la transparencia en la Administración de Justicia se concreta en la Carta de Derechos de los Ciudadanos ante la Justicia, aprobada como Proposición no de Ley por el Pleno del Congreso de los Diputados (22 de abril de 2002), y resultado del denominado Pacto de Estado para la Reforma de la Reforma de la Justicia (2001). Entre las prioridades que se marcan allí sobresale el principio de transparencia, desplegado en forma de derechos subjetivos vinculados al acceso a la información — general y actualizada - sobre el funcionamiento de los órganos judiciales y los procedimientos que se sustancian en estos últimos. El cumplimiento de estos compromisos se verá favorecido sin duda por la creación de unas estructuras — las Oficinas de Atención al Ciudadano- cuya implantación será generalizada en el conjunto del territorio nacional.

Seguidamente, el derecho — genérico- de acceso a la información tiene una concreción dentro de la Carta en un abanico de otros derechos con un perfil más específico. Algunos de alcance puramente institucional o administrativo (información electrónica normativa o la relativa a horarios de atención al público acceso a los documentos, libros, archivos y registros judiciales que no tengan carácter reservado). Otros de mayor relieve y alcance, referidos al ejercicio de la función «jurisdiccional» de los órganos judiciales, bien de carácter general (el estado, la actividad y los asuntos tramitados y pendientes; $y$ de aquellos procesos), bien con un afectación particular o individualizada para el ciudadano (contenido y estado de los procesos en los que tenga interés legítimo)

Aunque sin un valor normativo, al haber sido adoptada como proposición no de ley), se intenta remarcar la necesidad de que las previsiones del legislador lleguen a determinar la actuación de jueces y tribunales de justicia en su relación con los justiciables. Hacia esa dirección apunta la indicación que se hace sobre la necesidad de motivación de las resoluciones denegatorias del acceso o recepción de información (las autoridades y funcionarios expondrán por escrito al ciudadano que lo solicite los motivos por los que se deniega el acceso a una información de carácter procesal). La vocación de - poten- 
cial — normatividad queda en evidencia asimismo cuando, de forma abierta y expresa, se postula la eficacia de la Carta a través del derecho de los ciudadanos a exigir el cumplimiento. Estaríamos en presencia por tanto de un potencial derecho «justiciable» frente a los propios órganos judiciales.

La carta se impone pues como directriz necesaria para aquellas instituciones encargadas de velar por su efectividad (Ministerio de Justicia y las Comunidades Autónomas con competencias en la materia, el Consejo General del Poder Judicial, la Fiscalía General del Estado y los Colegios profesionales), mediante la adopción de las disposiciones oportunas y los medios necesarios. Para reforzar algo más esa pretensión de normatividad el legislador ha previsto la aplicación de un mecanismo de control parlamentario. De este modo, se va a encargar a la Comisión de Justicia del Congreso de hacer un seguimiento y evaluación del cumplimiento de los objetivos de transparencia; ese cometido se llevará a cabo a través de la información que le suministren, de forma periódica, tanto el Ejecutivo, como cualquier órgano del Estado a los que aquélla pueda solicitarla. La Carta contempla finalmente la presentación de una Memoria anual que se presenta al Parlamento (Cortes Generales) y al propio Consejo General del Poder Judicial (CGPJ); el contenido de este documento facilita indirectamente un conocimiento de la Administración de Justicia, utilizando como parámetro la exposición de las quejas, reclamaciones y sugerencias presentadas por los ciudadanos como consecuencia de un funcionamiento que se percibe como incorrecto o disfuncional. Por último, se ha previsto que toda esta información procedente de la actividad de los órganos judiciales se contenga y sea accesible a la ciudadanía en un Plan de Transparencia, en cuya confección participarán tanto las instituciones centrales (Ministerio de Justicia, CGPJ) como subestatales (Comunidades Autónomas).

Los compromisos que se adquieren en la esfera parlamentaria van a tener desarrollo pormenorizado en el Plan de Transparencia Judicial aprobado en el 2005. Entre los objetivos que inspiran esta iniciativa se subraya la necesidad prioritaria de solucionar el endémico problema de la opacidad judicial, obstáculo substancial para garantizar una adecuada transparencia institucional. ${ }^{35}$

Tomado como punto de partida y antecedente preferencial la Carta de Derechos del Ciudadano ante la Justicia (2002) y los informes de la Comisión para la Modernización del lenguaje jurídico (2009) ${ }^{36}$, el Plan de Transparencia judicial realiza una pormenorizada propuesta de indicadores necesarios en favor de una información de calidad sobre aspectos sustanciales del funcionamiento y actividad del Poder Judicial. En ese orden y para mejorar los niveles de comunicabilidad con la ciudadanía se señalan objetivos muy específicos; en forma de datos que permiten conocer, por ejemplo, la duración real de los procedimientos judiciales o el volumen de trabajo de cada

35 El contenido y alcance de este propósito general queda marcado también de forma bastante precisa: Proporcionar al ciudadano información general y actualizada sobre el funcionamiento de juzgados $y$ tribunales y sobre las características y requisitos de los distintos procedimientos judiciales

36 Vid. Informe de la Comisión de Modernización del lenguaje jurídico. https:// lenguajeadministrativo.com/wp-content/uploads/2013/05/cmlj-recomendaciones.pdf 
órgano judicial. Igualmente se marca como propósito del Plan asegurar la publicación en tiempo real los resultados de los procesos y de la ejecución de las sentencias. Parámetros como los anteriores permiten medir en parte el grado de eficacia y funcionalidad de la Administración de Justicia y, de este modo también, confeccionar lineamientos que — como se puntualiza — después sean útiles para proponer reformas y una mejor planificación presupuestaria en las inversiones que requiera el sistema de justicia.

El Plan de Transparencia destaca asimismo la importancia de mejorar el acceso a la información de la actividad judicial, proponiendo además como metodología la implantación de «herramientas» ${ }^{37}$, estructuras o instrumentos concretos para conseguir ese objetivo: Oficinas de Atención al Ciudadano, medios telemáticos (de fácil acceso) , y los propios canales institucionales que desde el Ministerio de Justicia y las CCAA se articulen para canalizar la información. Estadística judicial ${ }^{38}$; en un intento también de promocionar la interlocución activa entre los órganos judiciales y las ciudadanía ${ }^{39}$.

Otras fórmulas que pueden ser útiles para mejorar los niveles de transparencia judicial se contienen en el Protocolo de Comunicación de la Justicia 2018. Con esta iniciativa las instituciones principales del Poder Judicial en España (Tribunal Supremo, Consejo General del Poder Judicial) pretenden adaptar el funcionamiento de aquélla a la trascendencia mediática y social que está teniendo la actividad judicial ${ }^{40}$. En el documento se enfatiza el principio de publicidad como garantía esencial en el funcionamiento del Poder Judicial, al proporcionar confianza y legitimación social, además de ser una base en la que se sostiene el proceso debido, — afirma_ pilar del Estado de Derecho. El Protocolo prevé la canalización de la información judicial o de

37 El nivel óptimo de información y transparencia judicial se pretende lograr mediante los siguientes mecanismos:

- Articular un sistema razonable de acceso de profesionales y ciudadanos a la información sobre el estado en que se encuentran los procedimientos en que intervienen.

- Consultar sobre fechas y horas de los juicios a los que han de asistir los ciudadanos y los profesionales que les representan y defienden y otras incidencias que puedan llegar a producirse.

- Proporcionar a los Juzgados información sobre su propia actividad, por sí misma y en comparación con la información obtenida de los órganos de su mismo orden jurisdiccional y partido judicial, al menos.

38 Entre otras, se enuncian medidas con un perfil bastante definido, la unificación o compatibilidad de las aplicaciones informáticas que se emplean por las Oficinas judiciales, la implantación de Portales de Justicia en el Ministerio, el Consejo General del Poder Judicial, la Fiscalía General del Estado y las Comunidades Autónomas con competencias en materia de Administración de Justicia; se propone la «adecuación de los espacios judiciales», una medida necesaria de «arquitectura judicial» que garantizaría tanto el derecho de defensa como los principios de transparencia y publicidad.

39 En esta línea el Plan prevé un sistema que permite no sólo la presentación de quejas, reclamaciones y sugerencias de los ciudadanos, sino de igual modo la obligación por parte de los mismos órganos judiciales de donde tienen origen de dar una respuesta concreta con la mayor celeridad, y en todo caso en el plazo máximo de un mes.

40 Consultar en: https://www.poderjudicial.es/cgpj/es/Poder-Judicial/Tribunal-Supremo/Oficinade-Comunicacion/Protocolo-de-Comunicacion-de-la-Justicia/ 
Tribunales a través de las Oficinas de Comunicación, encargadas de suministrar información sobre todos aquellos asuntos que puedan tener interés en la opinión pública o sea conveniente dar a conocer, relacionados con la actividad y funcionamiento de los órganos judiciales ${ }^{41}$.

\section{EN TORNO AL DEBATE SOBRE SI LA TRANSPARENCIA UN DERECHO FUNDAMENTAL, DERIVADO DIRECTAMENTE DE LA CONSTITUCIÓN}

De salida no puede defenderse sin las necesarias cautelas la posible configuración de un derecho fundamental a la información (activa). Ciertamente la transparencia adquiere la condición de valor constitucional, por su evidente conexión con otros principios y valores del mismo rango (participación, información, rendición de cuentas, eficacia, eficiencia); un valor en buena lógica no absoluto, y por tanto susceptible de modulación en función de unos derechos constitucionales que delimitan y en su caso restringen su alcance (intimidad, protección de datos). Pero esa implícita fundamentación constitucional no ofrece la cobertura suficiente para derivar de aquélla la generación de un derecho público subjetivo, dotado de las características de inmediatez y aplicabilidad directa. Estas señas de identidad propias de una categoría especial de derechos, junto con los instrumentos jurisdiccionales de protección reforzada (amparo judicial y constitucional), creemos que no forma parte de la naturaleza jurídica de la transparencia informativa.

No obstante, tampoco cabe negar la afinidad que —en su calidad igualmente de derecho a la información (activa)— existe con otros derechos que sí integran el bloque de derechos fundamentales. En concreto, si se interpreta de manera flexible y dúctil la libertad consagrada en el artículo 20.1.d (esto es, la modalidad «pasiva» de la libertad de información) sería en potencia viable extraer de su contenido esencial ese mismo derecho a recibir información cuando aquélla procede de los poderes públi$\cos ^{42}$. Obviamente esto significaría aceptar la existencia de un derecho fundamental de extracción constitucional y potencial reconocimiento legal ${ }^{43}$, al que le serían apli-

41 Parece conveniente en este punto destacar la definición — bastante amplia — que se hace de ese concepto de «interés», como criterio de delimitación del contenido que debe ser objeto de divulgación: Un asunto se considerará de interés cuando despierte la atención de los medios de comunicación por las personas que intervienen, el objeto del proceso, la relevancia del becho objeto del procedimiento, la relevancia jurídica de las resoluciones dictadas y/o las normas jurídicas aplicadas, la previa existencia de informaciones periodísticas sobre el mismo, incluso en su fase policial, o se considere que es de interés para la ciudadanía.

42 Desde una tesis contraria a la hipótesis interpretativa que planteamos, Marc Carrillo considera que el derecho de acceso a la información no ha sido configurado constitucionalmente como un verdadero derecho fundamental, sino como un «principio jurídico». Vid. M. Carrillo, «Transparencia y derechos de acceso a la información en las administraciones públicas», cit., p. 269.

43 En una posición favorable se sitúan autores como I. Villaverde lo había hecho ya, y Fernando Rey, más recientemente. Éste último adopta un enfoque menos posibilisita o conservador, diferente al 
cables los mismos instrumentos de tutela que la norma fundamental establece para esta categoría privilegiada de derechos. La protección no sólo se mediría en el tipo de métodos procesales que cabría utilizar frente eventuales vulneraciones del derecho, sino en el hecho de que tendría que ser modulado o ponderado en régimen de paridad ante otros derechos —explícitamente fundamentales - con los que cuales puede entrar en colisión (intimidad, protección de de datos).

Entras las razones que favorecerían esta tesis de la fundamentalidad del derecho de información, se podría argumentar, en primer término y principalmente, la importancia de la trasparencia para el sistema democrático. Pero más en concreto, se le podría adjudicar ese carácter por su concurrencia ${ }^{44}$ con otros derechos que si tienen reconocida expresamente esa naturaleza. De un lado, la información o al acceso a los registros representa una garantía instrumental del derecho de participación (art. 23). De otra parte, y de manera más significativa, la transparencia informativa se podría considerar como el presupuesto una información pública libre en una sociedad democrática (art. 20).

A falta de una cláusula interna que autorice la ampliación del catálogo constitucional de derechos — al estilo de la XIX Enmienda de la Constitución de los EEUU— la vía «creativa» o «aperturista» para aceptar nuevos derechos fundamentales queda circunscrita en nuestro país a la regla interpretativa - preceptiva además_ que implanta el artículo 10.2 de la CE. Desde la perspectiva que ofrece el derecho internacional o convencional se podrían aportar argumentos para sostener la naturaleza fundamental del derecho de información. Concretamente los encontramos en una doctrina del TEDH que ha vinculado el derecho de acceso a la información con el derecho a recibir información del artículo de la CEDH (libertad de expresión). La analogía evidente con el derecho consagrado en el artículo art. 20.1d, justificaría adoptar como propias del ordenamiento constitucional la integración que el Tribunal de Estrasburgo lleva a cabo de ambos derechos ${ }^{45}$.

que habitualmente se utiliza ante el dilema de aceptar o no nuevos derechos constitucionales, aunque no hayan sido positivizados en el texto fundamental; para concluir que «el legislador no puede crear derechos fundamentales, pero sí puede reconocerlos a partir de su relación con otros derechos fundamentales expresos». Se trata de una capacidad condicionada o limitada a la «última palabra» del Tribunal Constitucional. En opinión del autor el carácter fundamental del derecho a la información se basa en la conexión o integración implícita en el contenido de los derechos fundamentales de los artículos 20.1.d y 23.1 (derecho a recibir información veraz y derecho a participar directamente en los asuntos públicos, respectivamente). Vid. I. Villaverde; Los derechos del público, Tecnos, Madrid, 1995, p. 118). Y F.Rey, «Quod omnes tangit ab omnibus cognitum es-se debet: el derecho de acceso a la información pública como derecho fundamental», Cit., pp. 12 y ss.

44 Vid. L. Cotino Hueso, «Algunas propuestas de mejora de la normativa del derecho de acceso a la información», Dilemata, núm. 27, 2018, pp.263-279. El autor analiza también en este trabajo las reformas que sobre la Ley 19/2013, contenía la Proposición de Ley Integral de Lucha contra la Corrupción y Protección de los Denunciantes, presentada por el Grupo Parlamentario de Ciudadanos.

45 Los casos más significativos serían los contenidos en las sentencias Társaság a Szabadságlogokért (2007), Kenedi contra Hungría (2009) , Youth Initiative for Human Rights contra Serbia (2013); y más recientemente Magyar Helsinki Bizottság contra Hungría (2016). Citadas por F. Rey (cit., p. 16 y ss) 
Todavía en el orden internacional, la Carta de Derechos de la UE confirma esa tendencia a reforzar el acceso a la información como derecho individual; además con una comprensión autónoma y no necesariamente vinculada o dependiente de la libertad de expresión o de información. De este modo, el «Derecho de acceso a los documentos» (art. 42) implicaría que "Todo ciudadano de la Unión o toda persona física o jurídica que resida o tenga su domicilio social en un Estado miembro tiene derecho a acceder a los documentos del Parlamento Europeo, del Consejo y de la Comisión». 46

A propósito de la trascendencia tendría el hecho de que la transparencia —en su versión de información activa - recibiera un enunciado expreso en el texto constitucional, cabría diferenciar entre dos posibles modalidades de formulación. Obviamente las consecuencias podrían ser muy distintas si se positivizara como otro principio más de los que genéricamente deben informan el funcionamiento y la actividad de las Administraciones Públicas; o bien si se incluyera en el catálogo de derechos constitucionalizado, como derivado del derecho o libertad fundamental a la información. En este segundo supuesto, su desarrollo normativo básico y principal abriría el camino posiblemente a la dimensión participativa, hasta el momento escasa o relativamente implementada en las legislaciones sectorial (Transparencia) o general (LRJPAC). Complementaría por otro lado el carácter vinculante de las obligaciones que en materia de transparencia derivan ya de esta esfera legal, y reforzaría seguramente la operatividad de los sistemas de control.

y L. Cotino Hueso, «El reconocimiento y contenido internacional del acceso a la información pública como derecho fundamental», cit., pp. 279-316. En el marco de esta doctrina jurisprudencial el Tribunal de Estrasburgo ha venido sosteniendo la teoría de la «conexión»: de tal modo que la «libertad de recibir información» (art. 10.1 del Convenio) «abarca un derecho de acceso a la información » (Sentencia Youth Initiative for Human Rights c. Serbia , de 25 de junio de 2013. La posición y sus respectivas modulaciones del TEDH puede quedar sintetizada en los siguientes pronunciamientos: «tal derecho $u$ obligación puede surgir (...) en circunstancias en que el acceso a la información es fundamental para el ejercicio individual del derecho a la libertad de expresión, en particular, de «la libertad de recibir y difundir informaciones» (art. $10 \mathrm{CEDH}$ ) y su negación constituye una interferencia con este derecho». Seguidamente se encarga de relativizar las consecuencias y el alcance real de esa interacción entre derecho de expresión y de información: «el derecho a recibir la información no puede ser interpretado como que impone a un Estado obligaciones positivas de recopilar y difundir información de oficio (...) el articulo 10 no confiere a los particulares un derecho de acceso a la información en poder de una autoridad pública, ni obliga al Gobierno a dar dicha información a la persona». En todo caso, la posibilidad de reconocimiento de un derecho de información (o a la información), efectivo y con fundamento en la norma convencional no se extiende al conjunto de los ciudadanos, sino que va a quedar circunscrito — según la tesis más consolidada que ha venido defendiendo el TEDH - a algunos titulares que tienen un interés específico o profesional con el conocimiento y la divulgación de la información (periodistas, ONGs, investigadores y académicos y determinados usuarios de redes sociales). A su vez, la modulación de la posición anterior se puede reconocer en otra resolución en la que amplifica la potencial titularidad del derecho (caso Magyar Helsinki Bizottság c. Hungría, 2016).

46 Una concepción subjetiva y fundamental que encuentra igualmente apoyo en la esfera legislativa (Reglamento 1049/2001 y la jurisprudencia europea (STJUE Suecia/Comisión, C 64/05), en donde se establece un criterio restrictivo a las posibles excepciones que se puedan aplicar a ese derecho ().Vid. L. Cotino, cit., p. 66. 


\section{BALANCE, DUDAS Y ALGUNAS CRÍTICAS SOBRE EL DERECHO DE INFORMACIÓN ACTIVA EN LA LEY 19/2013}

A modo de primera valoración conclusiva sobre la manera en que se han implementado el principio de Transparencia en su modalidad de Publicidad activa podría ponerse en duda la utilidad real del acceso sobre contenidos puramente orgánicos, funcionales o competenciales; al menos desde el punto de vista del hipotético control social que se pretende lograr con la puesta en funcionamiento de las webs institucionales. Ciertamente aportan una información estructural que sirve para el conocimiento de los órganos y entidades públicas. Pero la visualización de este tipo de datos genéricos, institucionales o jurídicos, apenas si tiene eficacia como instrumentos que hagan más transparente los resortes y mecanismos que explican su funcionamiento interno; allí donde es más necesario el acceso y conocimiento por parte de la ciudadanía.

Con la Ley 19/2013 la transparencia ha superado su configuración previa como principio programático que se despliega legalmente en un deber genérico de eficacia diferida y de proyección parcial (en cuanto soportes y contenido de la información); para convertirse en un principio generador de obligaciones jurídicas de aplicabilidad inmediata y directa exigibilidad. Sin embargo, posiblemente la finalidad principal que impulsó la aprobación de aquella norma no se hay cumplido plenamente. No se ha profundizado lo necesario en el proceso de «democratización informativa» como fórmula indirecta que contribuya a una verdadera «regeneración democrática», si bien es cierto que se han abierto canales para una intensificación del control social de los poderes públicos, tanto de su actividad institucional como de aquella que tiene una trascendencia económica y financiera de los agentes políticos.

Entre los déficits que cabe señalar de la ley en el ámbito de la transparencia información, uno de los más significativos sería el que afecta a la articulación de la función de control que lleva a cabo el Consejo de Transparencia y Buen Gobierno. La ley circunscribe a la Administración General del Estado la supervisión que llevará a cabo el denominado Consejo de Transparencia y Buen Gobierno. Quedan por consiguiente fuera de su ámbito subjetivo de fiscalización todo un conjunto de instituciones y agentes que han demostrado su reconocida implicación en casos de corrupción (partidos políticos, órganos de otras Administraciones territoriales no estatales). La relativización de los niveles de control resulta patente en esta otra categoría de sujetos de naturaleza pública —o que desempeñan funciones de relevancia pública- a los que no se les podría aplicar el régimen sancionador por infracciones del derecho de información, aun cuando forman parte del espacio institucional al que se refieren las obligaciones de transparencia.

Por otro lado, y aunque en lo relativo a la información con «relevancia jurídica», habría que reconocer un progreso en cuanto al ámbito subjetivo/institucional de 
proyección $^{47}$, se pueden apreciar en la Ley 19/2013 algunos aspectos susceptibles de perfeccionamiento. En este sentido, la información activa debería proporcionar algo más que una simple «descripción orgánico-funcional» de las organismos y entidades organismos a los que se aplica el mandato legal. Ciertamente la promoción de los estándares democráticos a través de esta modalidad de transparencia informativa, está directamente relacionada con la ampliación de la publicidad esencialmente estructural o competencial. No parece que sea especialmente significativa la aportación de la Ley 19/2013 a la hora de definir los canales y la metodología que permitan canalizar una participación mejor y de más calidad en los procedimientos administrativos que se activan para la elaboración de normas reglamentarias y la adopción de actos administrativos; sin duda un vacío legal que en nada favorece la operatividad de la norma ${ }^{48}$.

Lo que determinaría un salto cualitativo sería la posibilidad de suministrar datos no sólo sobre las resoluciones o actos administrativos, sino también sobre los aspectos relevantes de los procesos decisionales para la formación de aquéllos que se producen en el seno de los órganos de la Administración, así como el comportamiento en ellos de los actores con capacidad de influir en las decisiones oficiales de las Administraciones.

De igual modo, sería de considerable interés para la ciudadanía tener la oportunidad de conocer y disponer de información sobre otros aspectos importante e indicativos de los efectos y consecuencias de la actividad de esos organismos públicos, como la evaluación de calidad administrativa y autoevaluación o el efecto y eficacia real de los Planes. Sin embargo, parece razonable aplicar algunos límites al conocimiento público de determinados procesos políticos (negociaciones parlamentarias para la formación del Gobierno), aunque en cierto modo el contenido de esos acuerdos se pueda reconocer indirectamente en la evaluación y desarrollo de los debates parlamentarios que tienen lugar para la aprobación de las leyes, y de cuya información da cuenta la documentación que se pone a disposición de la ciudadanía a través de los Boletines oficiales de las instituciones legislativas (Cortes Generales, Asambleas Legislativas de las CCAA). Tampoco resulta lógico que se ponga luz y taquígrafos a ese otro tipo de negociaciones que se producen normalmente en la fase previa al juicio oral entre el Ministerio Fiscal y la parte sometida a procesamiento criminal.

47 Pese a que supone en efecto un ampliación respecto de la LRJPAC, quedan no obstante fuera del alcance de la información pública espacios de la actividad jurídica con una importante repercusión para asegurar los fines de la transparencia; es el caso de los informes de Abogacía del Estado e Intervención, cuya importancia ha quedado de manifiesto en uno de los casos más «emblemáticos» de corrupción política que ha tenido lugar recientemente en nuestro país (caso ERES, Andalucía). Vid. M. Villoria, «Publicidad activa», en La Ley de Transparencia, Acceso a la Información, Publica y Buen Gobierno, (I. Wences, M. Kölling, S. Ragone (coords.), Centro de Estudios Políticos y Constitucionales, EPC, Madrid, 2014.

48 Apenas se innova entonces el tradicional trámite de audiencia en los procedimientos administrativos consignado en el artículo 105 (a y c) de la CE, y más tarde desarrollado en la ley. 
Otro ámbito de notable interés público son las Actas de Consejos de Ministros. En la actualidad se pueden llegar a conocer las Actas de los Consejos (celebrados desde 1996), con los órdenes del día, asuntos tratados y los acuerdos alcanzados; aunque se observan aún déficits entre lo acordado realmente y aquello sobre lo que finalmente se proporciona información; como tampoco se facilitan los documentos utilizados para alcanzar esos acuerdos ${ }^{49}$. En cualquier caso, sigue todavía vigente una limitación prevista en la Ley del Gobierno (art. 5.3: Las deliberaciones del Consejo de Ministros serán secretas), que autoriza a permanecer fuera del escrutinio de la ciudadanía una parte importante del funcionamiento interno del órgano colegiado gubernamental; prescripción modulada en parte por una interpretación flexible del Consejo de Transparencia y Buen Gobierno.

Quedan por último algunas dudas en lo que respecta a la aplicación del régimen sancionador previsto en la Ley 19/2013. En primer lugar, al tener la consideración de normativa básica, es posible —y legítimamente probable — que las CCAA puedan relajar los niveles de exigencia en algunas de las prescripciones marcadas en la ley estatal. Por otra parte, sigue existiendo un grado de indeterminación notable en una adjetivación —incumplimiento «reiterado»— sobre las causas que permiten la determinación exacta de aquellas infracciones que se consideran graves y por tanto autorizan eventualmente la aplicación de ese sistema sancionatorio. De igual modo, se pueden plantear incertidumbres razonables a la hora de delimitar la responsabilidad subjetiva de un posible incumplimiento en el marco de una estructura jerarquizada, donde la capacidad decisoria se encuentra distribuida entre los diferentes niveles que la componen. Además, es necesario anotar que el órgano que tiene competencia para registrar posibles incumplimientos de la Ley, no dispone sin embargo de facultades para imponer las sanciones que aquéllas conllevan, estando sólo capacitado para instar en otras instancias la apertura del procedimiento sancionador.

A título de conclusión final, la eficacia de los instrumentos normativos a través de los cuales se articula el derecho/principio «constitucional» de trasparencia informativa no va a depender exclusivamente de implementar soluciones de naturaleza jurídica. No se trata de sólo de resolver los posibles déficits de legislación vigente, confeccionando nuevos métodos de divulgación o abriendo otros ámbitos materiales

49 En la situación actual generada por el coronavirus se está requiriendo desde los medios de comunicación, y se percibe así mismo como una demanda generalizada entre la ciudadanía, una información más detallada sobre los procesos de toma de decisiones que se están adoptando a la hora de fijar las medidas que se aplican como consecuencia de la declaración del estado de alarma por Real Decreto 463/2020, de 14 de marzo. De hecho, están siendo objeto de una crítica en absoluto infundada las lagunas de información activa que se observan en la web del Gobierno central para poder acceder y tener conocimiento sobre algunos de los criterios y datos científico-técnicos que se están utilizando en las comisiones y grupos de expertos que están trabajando en la adopción de medidas contra la pandemia. La excesiva discrecionalidad gubernamental en este punto creemos que no tiene un fácil un control con los mecanismos que se han previsto en la Ley de Transparencia; un dato éste a tener en cuenta para una hipotética reforma legislativa que en éste, al igual que en otros muchos ámbitos del ordenamiento, está planteando ya como exigencia insalvable la post-pandemia. 
al conocimiento y participación ciudadana. Ni tampoco basta el perfeccionamiento en términos de técnica legislativa de los medios que se prevean para el cumplimiento de objetivos y mandatos legales. Creemos que el éxito de las operaciones regulativas en materia de transparencia depende también en gran medida de factores de índole cultural. En este punto conviene subrayar una paradoja, ya que mientras subsisten espacios de opacidad en la actividad de los poderes públicos, es cada vez mayor la sensibilidad y la percepción social en torno a la necesidad de que su funcionamiento debe estar guiado por la transparencia informativa.

Title:

The constitutional dimension of the principle of transparency and the «active» information right

\section{Summary:}

1.- Introduction: the constitutional dimension of the Principle of Transparency. 2.- Constitutional formulations of the «active information». 3.- Law 19/2013, of December 9, about Transparency, Access to public information and Governance. A legal reform partially innovative. 3.1.The legislative configuration of the principle of transparency. 3.2.- The «active» information as the instrument of the transparency. 3.3.- The institutional guarantee of active information: Transparency and Governance Council. 3.4.- The Ombudsman and the control of transparency. 4.- The obligation of transparency in the Judicial Power. 5.- The constitutional and fundamental right to transparency and public information. 6.- Some conclusions, doubts and criticisms about the right to active information in Law 19/2013

\section{Resumen:}

La transparencia y el derecho a la información son elementos esenciales en un Estado democrático de derecho. Pero la ausencia por lo general en los textos constitucionales de una formulación explícita de estos principios no es un obstáculo para reconocer su vinculación con principios y derechos constitucionales. La información además es un principio que genera un conjunto de obligaciones para las instituciones públicas, y especialmente a las judiciales y administrativas (información activa). La Ley 19/2013, de 9 de diciembre, de transparencia, acceso a la información pública y buen gobierno representa una iniciativa importante, si bien sólo parcialmente 
innovadora. La «información activa» se configura como un principio instrumental y obligatorio para las Administraciones públicas, si bien no como un derecho accionable por el ciudadano. El Consejo de Transparencia y Buen Gobierno se convierte en la principal garantía de las obligaciones de información activa que impone la Ley de 2013. El principio de transparencia se aplica igualmente, aunque con algunas especialidades, en la Administración de Justicia. Sin embargo, la relevancia progresiva del principio de trasparencia no permite afirmar la existencia de un verdadero derecho fundamental a la información activa; aunque se pueden defender argumentos que refuerzan su potencialidad jurídica. Finalmente se hace un balance crítico de los déficits y mejoras que necesitaría la vigente legislación.

\section{Abstract:}

Transparency and the right to information are essential elements in a democratic state. Generally, the constitutions do not mention explicitly these principles. They are in connection with some constitutional principles and rights. Information is also a principle that generates a set of obligations for public institutions, and especially for judicial and administrative ones (active information). The Act 19/2013 about transparency, access to public information and governance represents an important initiative that has updated partially the Spanish legislation. «Active information» has been configured as an instrumental and obligatory principle for public administrations, although not as a right that can be acted upon by the citizen. The Transparency and Governance Council becomes the main guarantee of the active information obligations imposed by the 2013 Act. The principle of transparency has been applied with some specialties in the Administration of Justice. However the progressive relevance of the principle of transparency, it not possible to affirm the existence of a true fundamental right in order to access to active information; but we can defend some arguments that reinforce its juridical value. Finally, the essay reveals the deficits and improvements that the present legislation would require.

Palabras clave:

Constitución; transparencia; información activa; derecho

Key words:

Constitution; transparency; active information; right 